\title{
Analysis of the influence of rapid filter cycle interruption on filtrate quality
}

\author{
M. Zielina ${ }^{1} \mathbb{D}$
}

Received: 21 December 2020 / Accepted: 30 August 2021 / Published online: 3 September 2021

(c) The Author(s) 2021

\begin{abstract}
The article presents research carried out on a sand/anthracite filter in a water treatment plant in Cracow in the south of Poland. These studies show that shutting down the filter after only three hours of operation, setting it aside for four hours and restarting without backwashing did not cause any visible deterioration in the quality of the produced filtrate. Stopping the same filter for four hours, however, after $68 \mathrm{~h}$ of operation, visible deterioration in the quality of the filtrate can be observed. After a significant initial deterioration, the quality of the filtrate slowly improved and after a few hours, it reached a level comparable to that before the filter was taken out of service. This was probably the result of characteristic changes in shear stress at the boundary of the deposit and flowing water in the capillaries, which accompanied changes of filtration rate. Decrease in the removal efficiency of coarser particles lasted longer and was greater than that of finer particles. Decrease in particle removal efficiency after restarting the dirty filter was difficult to identify by turbidity measurements, but clearly identifiable by measuring suspended solid concentration and the number of coarser particles. Interrupting the operation of a rapid filter shortly after it has been backwashed should not significantly reduce its efficiency, but after prolonged operation, it may adversely affect the quality of the filtrate.
\end{abstract}

Keywords Water quality $\cdot$ Drinking water $\cdot$ Rapid filtration $\cdot$ Particle size

\section{Introduction}

Over the past decades, a lot of research into new and wellknown water treatment technologies has been performed. Recently, a significant increase in the concentration of natural organic matter has been observed in freshwater, as well as municipal wastewater. This has justified the great interest of scientists worldwide in processes characterised by high efficiency of organic matter removal, such as adsorption, membrane filtration, oxidation, biofiltration and coagulation (Sillanpää 2018, Pietrzyk 2018, Domoń 2018, Bielski 2017, Mroczko 2020). Depth filtration, however, is not included among them, even though it is an indispensable process, which is sometimes used as a pre-treatment of membrane, biological or activated carbon filters (Uragami 2017), sometimes preceded by in-line flocculation, but most often used as the main process for the reduction in fine particles and

M. Zielina

michal.zielina@pk.edu.pl

1 Faculty of Environmental and Energy Engineering, Cracow University of Technology, Cracow, Poland flocs remaining after flocculation followed by sedimentation (Hendricks 2001). There is a number of filtration materials that are used, such as quartz, anthracite, activated carbon, garnet, glass, melaphyre, zeolite and diatomaceous earth (Michel 2017, Logsdon 2002). Quartzite sand, however, is still the most popular single-layer material, anthracite/ quartzite is a double-layer configuration and anthracite/ quartzite/garnet a triple-layer configuration. The use of multilayer media allows the filter to work efficiently, with slowly increasing pressure head loss over time. This allows less frequent backwash of the media and, thus, saves energy used for this purpose. The same effect of longer filtration cycles can also be achieved with the so-called regulation filters with declining rate filtration (Zielina and Dąbrowski 2011, Mackie 2003). Long periods without backwash require detailed inspection of the filtrate to avoid deterioration of the filtrate quality. Therefore, it is quite common in developed countries to measure the quality of filtrate online. Unfortunately, this measurement is usually only carried out at the collective outlet of the entire filter station, and not at the outlets of individual filters. Rarely, apart from turbidity measurement, the number of particles in particular size groups is 
measured (Zielina 2011). This allows the precise determination of the optimum moment for backwash, which should appear just before the quality of the filtrate deteriorates. This deterioration is caused by the increasing filtration rate inside the capillaries and, consequently, by the increasing shear stress in the pores of the bed. Usually, an increase in thicker particles or flocs in the filtrate is observed first, and later on in finer ones (Tien 2007, Zielina 2016). The turbidity measurement alone may not show a decrease in the removal efficiency of particles from one size group, which may occur after exceeding a certain degree of clogging or be caused by sudden changes in filtration rate. As shown (Zielina 2016), turbidity measurements are mainly influenced by particles scattered in water with sizes below $2 \mu \mathrm{m}$. This influence decreases with increasing particle size. Therefore, it can be expected that a change in the number of particles with sizes above $10 \mu \mathrm{m}$ may have a negligible effect on turbidity measurements. A change in the filtration rate can occur when the filters are shutting down and restarting. This can cause a sudden increase and decrease in shear stress inside the capillaries at the boundary of flowing water and retained sediment. As shown in works (Barnes 2000, 1997) during laboratory tests on thixotropic fluid, a sudden increase in shear rate in the rheometer caused a sudden increase in shear stress, exceeding that which would appear at the same shear rate but under stable conditions. Then, maintaining a constant shear rate, the shear stress gradually decreased to a constant value. Sometimes, rapid filters are stopped at peak times when electricity prices are highest and are used to reduce water production costs. According to the described laboratory observations on the rheometer, and on the technical scale in the filters, an increase in shear stress can be expected when the filter is restarted to a value significantly exceeding the values achieved with continuous stabilised filter operation. It can also be expected that a decrease in shear stress to the values achieved before setting the filter aside can last for some time. It is, therefore, necessary to check whether filter stoppages during operation have an impact on the quality of the produced filtrate and, if so, what that impact is. The ways in which the quality of the filtrate is changed when the filter is removed from the service and restarted without backwash after a while have already been tested in a water treatment plant in Carrollton, Georgia (Logsdon 1990). Filters that had been operated, stopped and returned to service without backwash produced water with turbidity ranging between 0.2 NTU and 3.2 NTU, whereas filters that had been operated continuously produced water with much lower turbidity, from 0.07 to 0.18 NTU. In another example at the Duluth Water Filtration Plant (Logsdon 2002), the influence of cycle interruption on filtrate quality was tested. The main purpose of the plant was to remove amphibole asbestos from Lake Superior. Alum was the coagulant, and a non-ionic polymer was used to strengthen the flocs. Dual filter media were stopped and restarted without backwashing. Only very slight increase in filtrate turbidity was observed after filter restarting. Only in filters that had accumulated more than two thirds of the usual terminal head loss, did asbestos fibre count peak above 0.1 million fibres per litre, when normally they vary between 0.02 and 0.05 million fibres per litre. Detailed analysis of the effects of filtration cycle interruption on the removal of turbidity, particle counts, suspended concentration, as well as particles in different group sizes, is desirable. The deterioration of filtrate quality produced by the filter under shorter and longer operation times following backwash should also be tested.

\section{Materials and methods}

\section{Water treatment plant}

The research was conducted at one of Cracow's water treatment plants in southern Poland on the Raba River. Raw water for this station is taken from the Dobczyce reservoir and pumped from the intake into a contact reservoir, where it is preoxidised with ozone. Following ozonisation, the water flows into the mixing and distribution chambers, where chemicals are dosed. First, activated carbon in the form of pulp is dosed, followed by coagulant. Here, the separation into two distinct process lines takes place. Some of the water flows out to the Raba I process line and the remaining flows into four accelerators in the Raba II process line. The analysed filter station was located in the Raba I process line. The water in the Raba I process line flows through the mixing chamber and then it is separated into 12 vortex chambers, from which the suspension flows out through a drainage channel and gets to horizontal settling tanks with a capacity of $670 \mathrm{~m}^{3}$. From the sedimentation tanks, the water flows into a common trough and gets to the filters. Limestone milk is dosed into a trough supplying the suspension to the filter. The water from the collecting trough is distributed to the individual rapid filters. The technological diagram of Raba I water treatment line with marked water sampling points and the filter examined in experiments is shown in Fig. 1.

\section{Laboratory set-up}

The water supply to the filters is above the water table on the filter. The water level on the filters is measured with an ultrasonic probe. The outlet pressure is recorded by an Aplisens pressure sensor. The flow through the filters is calculated for a known level in the inlet trough. The filter under examination is filled with an anthracite-sandy bed of about $100 \mathrm{~cm}$ in height. The granulation of individual layers of the bed is shown in Table 1 . The initial porosity of the quartz sand was 0.41 , while that of the anthracite was 0.56 . 


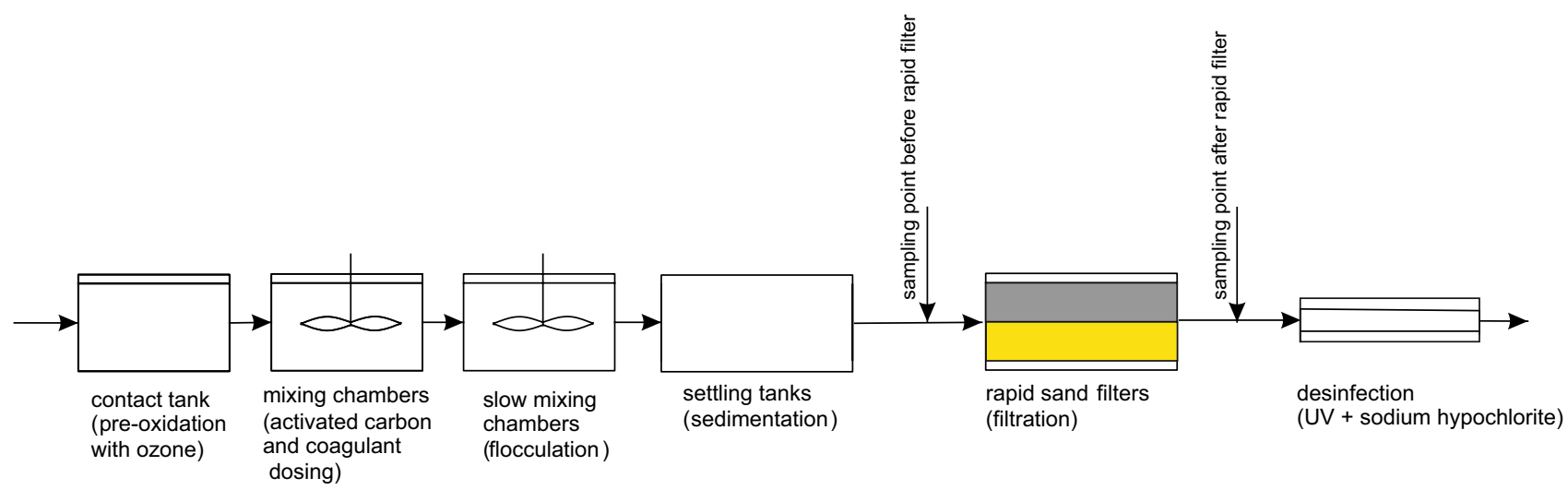

Fig. 1 Technological scheme of Raba I water treatment process line with sampling points before and after rapid filtration

Table 1 Stratification of grains of sand/anthracite bed

\begin{tabular}{ll}
\hline Grain size $[\mathrm{mm}]$ & $\begin{array}{l}\text { Layer } \\
\text { height } \\
{[\mathrm{cm}]}\end{array}$ \\
\hline Anthracite layer & \\
$0.9-1.1$ & 15 \\
$1.1-1.3$ & 20 \\
$1.3-1.5$ & 15 \\
Quartz sand layer & \\
$0.5-0.63$ & 10 \\
$0.63-0.8$ & 23 \\
$0.8-1.0$ & 17 \\
\hline
\end{tabular}

Table 2 Experimental parameters

\begin{tabular}{llll}
\hline $\begin{array}{l}\text { Filtration rate } \\
{[\mathrm{m} / \mathrm{h}]}\end{array}$ & $\begin{array}{l}\text { Temperature } \\
{[\mathrm{C}]}\end{array}$ & $\begin{array}{l}\text { Initial porosity } \\
\text { of the quartz } \\
\text { sand }\end{array}$ & $\begin{array}{l}\text { Initial porosity } \\
\text { of the anthracite }\end{array}$ \\
\hline 2.32 & 12.2 & 0.41 & 0.56 \\
\hline
\end{tabular}

Table 3 Particle size distribution in suspension flowing into the filter during the experiments

\begin{tabular}{lllll}
\hline Particle size range $[\mu \mathrm{m}]$ & $2-5$ & $5-10$ & $10-25$ & $25-80$ \\
Particle number $[1 / \mathrm{ml}]$ & 21,373 & 6761 & 1144 & 22 \\
$\begin{array}{c}\text { Volumetric particle con- } \\
\text { centration }[\mathrm{ppm}]\end{array}$ & 0.35 & 1.25 & 1.42 & 1.43 \\
\hline
\end{tabular}

During the experiments, the values of filtration speed and temperature were maintained at a level consistent with the values given in Table 2 .

The number of particles flowing into the filter in particular size ranges is given in Table 3. The average turbidity in water flowing into the filter was $7 \mathrm{NTU}$, the average total number of particles flowing into the filter was $29,300[1 / \mathrm{ml}]$, suspended solids concentration was 4.7 [ppm], the average $\mathrm{pH}$ value was 7.9, conductivity was $0.23 \mathrm{mS} / \mathrm{cm}$ and the zeta potential was $-13.5 \mathrm{mV}$ at the given $\mathrm{pH}$ and conductivity.

The multilayer bed on which the verification experiments were carried out guaranteed the elimination of straining during filtration.

Particle count measurement was carried out using the Liquilaz E20 spectrometric particle counter by particle size measurement. Nephelometric turbidity was measured using a turbidity meter by WTW - Turb 555 IR.

\section{Study method}

The measurement was carried out for one complete filtration cycle, from the time one backwash of the filter was completed until another backwash was required. The total running time of the experiment was $88 \mathrm{~h}$, or just under 4 days. The first measurement was carried out after the first hour from the end of backwash, the next after another two hours, and subsequent measurements were carried out at a frequency of every $5 \mathrm{~h}$, until the end of the study.

Water samples for analyses were taken at the inflow and outflow to/from the filter. Water turbidity, total number of particles in water and suspended solids concentration were measured. Based on these parameters, the filtration efficiency curves were determined.

Water temperature and filtration velocity were monitored during the experiments.

\section{Results}

Research was carried out on one of the filters included in the water treatment plant on the Raba River. The characteristics of this filter are discussed in the materials and methods section. A full filtration cycle between consecutive backwashes, which lasted almost $90 \mathrm{~h}$, was examined. Such a 
long filtration cycle is possible due to the two-layer media applied in the filters and the highly effective processes preceding filtration. The course of changes in the efficiency of removing particles from particular size groups is shown in Fig. 2. The efficiency of removing turbidity, suspension concentration and the total number of particles are shown in Fig. 3.

The removal of particles from particular size groups indicates their high efficiency throughout the filtration process. No deterioration of the filtrate quality was observed despite the long filter cycle and relatively low temperature. This was caused by conditioned inlet suspension and multilayer media in the filter allowing for the accumulation of particles across the entire cross section. Unusually, the removability of coarser particles was lower than that of the finer ones. To the contrary, the removability of nephelometric turbidity and total number of particles were similar to that of the finest particles, as normal. The removability of suspended solids concentration was lower than that of turbidity, which probably resulted from the lower removability of coarser particles, which have a dominant influence on the suspended solids concentration value.
Fig. 2 Efficiency of removing particles from particular size groups
Fig. 3 Efficiency of removing turbidity, suspension concentration and total number of particles
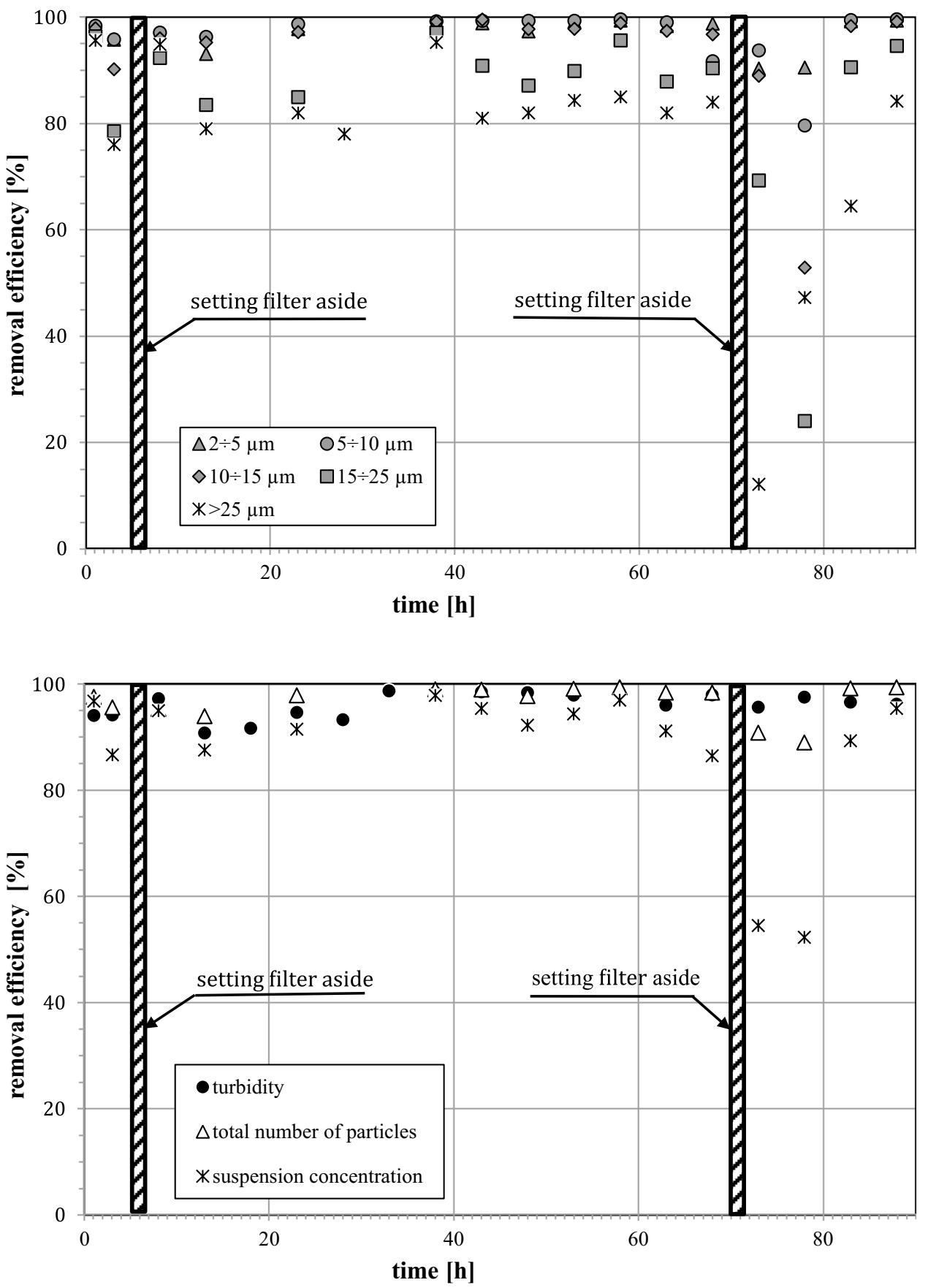
During the research, the filter was stopped twice, interrupting its operation, as shown in Figs. 2 and 3. The first time was after four hours of filtration, when a small amount of deposit was collected, and the second time after $69 \mathrm{~h}$, when the filter was significantly filled with particles trapped in the media pores. As can be seen in Figs. 2 and 3, after the filter had been set aside for a few hours during the first stage of the cycle, the efficiency of the removal of turbidity, the concentration of suspended solids, as well as the total number of particles and particles from particular size groups did not deteriorate, or even slightly improve. Conversely, upon restarting the same filter, which was set aside for a few hours after many hours of operation, a significant deterioration in the removal efficiency of turbidity, suspended solids concentration, as well as the total number of particles and particles from particular size groups was observed. The reduced efficiency of the filter operation continued for a few more hours, with the efficiency of removing larger particles and suspended solids concentrations deteriorating more than turbidity. If the filter is operated for a long period of time, stopped and then restarted without backwashing, a significant increase in shear stress associated with restarting can flush out particles trapped in the filter bed. In the case of filters operated for a short period of time, such a significant increase in shear stress is not expected, and thus the retained particles will not be detached. It is likely that the sudden increase in filtration rate that accompanied the start of the filter caused an increase in shear stress in the bed, which could have caused the previously retained particles to break off, while also reducing the efficiency of retaining the particles flowing through the filter. A change in the quality of the filtrate could also be caused by a change in the quality of water flowing into the filter, but no significant changes in the concentration and size distribution of the particles or parameters such as zeta potential and $\mathrm{pH}$ in the suspension flowing into the filter were observed. It is likely that the significant decrease in particle retention efficiency after returning the filter to service, not observed with a much cleaner filter, is caused by suffusion. Under laboratory conditions, a sudden increase in shear rate caused a rapid and significant increase in shear stress, which in subsequent moments, while keeping the rate constant, gradually decreased to a constant value (Barnes 2000). These laboratory observations (Barnes 2000) confirm the experimental measurements carried out at the station, the results of which are shown in Fig. 2 and 3. Returning the filter to service again after a period of downtime caused a sudden increase in flow velocity inside the bed channels, this was probably accompanied by a sudden and significant increase in shear stress, higher than that which we would observe during the operation of the filter without periodic setting aside.

Hence, the significant decrease in the removal efficiency of turbidity, suspended solids and particles observed in
Figs. 2 and 3, when the filter was put back into operation, was comparable to the removal efficiency before the filter was stopped, although the filtration rate was the same. The reduced particle removal efficiency was maintained for a few more hours and mainly concerned the thicker particles and suspension concentration rather than the finer ones and nephelometric turbidity. After ten hours, the efficiency of all particles except the coarsest ones returned to the level observed before the filter was stopped. The gradual, albeit lasting for several hours until stabilisation, increase in particle removal efficiency is confirmed by the slow, long-term decrease in shear stress after a sudden increase in speed.

As can be seen in Fig. 2, the removal efficiency of the largest particles, after only $15 \mathrm{~h}$, reached the value before setting the filter aside, whereas the finer particles reached this value after less than ten hours. In the case of turbidity, a slight decrease in its reduction can be observed immediately after the filter is restarted but, soon afterward, the reduction efficiency of this parameter increases to reach the values from before it was stopped.

\section{Conclusions}

(1) The analysis indicates that stopping the dirty filter for a few hours and restarting it without backwashing may cause significant deterioration in filtrate quality. Therefore, interrupting the filter in later periods of the cycle is not recommended.

(2) After restarting the dirty filter without backwash, a larger and more durable reduction in the removal efficiency of coarser particles, and a smaller and shorter reduction in the removal efficiency of finer particles was observed. After just ten hours, the efficiency of removing the number of fine particles in the filtrate has reached a value before the filter stops and after $15 \mathrm{~h}$ for coarser particles.

(3) Changes in filtrate quality were caused by a sudden change in filtration rate inside the filter capillaries after the filter was restarted and the accompanying shear stress changed. The course of these changes is confirmed by observations in laboratory conditions on the rotameter scale, according to which a sudden increase in shear rate to a subsequently maintained constant level causes a significant increase in shear stress in the deposit, which gradually decreases to a constant value. A significant increase in shear stress causes the washing of particles trapped within the filter bed.

(4) The drop in particle removal efficiency after restarting the dirty filter without backwashing was difficult to identify from turbidity measurements, but it was clearly visible from the suspended solids concentration and total particle counts measurements.

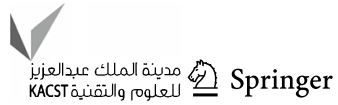


(5) Stopping the filter while it is filled with a small amount of accumulated sediments four hours after backwashing for a few hours and restarting did not cause any deterioration of the filtrate quality.

Funding The author has no relevant financial or non-financial interests to disclose.

Data Availability Availability of data and material is not restricted.

\section{Declarations}

Conflicts of interest The author has no conflicts of interest to declare that are relevant to the content of this article.

Open Access This article is licensed under a Creative Commons Attribution 4.0 International License, which permits use, sharing, adaptation, distribution and reproduction in any medium or format, as long as you give appropriate credit to the original author(s) and the source, provide a link to the Creative Commons licence, and indicate if changes were made. The images or other third party material in this article are included in the article's Creative Commons licence, unless indicated otherwise in a credit line to the material. If material is not included in the article's Creative Commons licence and your intended use is not permitted by statutory regulation or exceeds the permitted use, you will need to obtain permission directly from the copyright holder. To view a copy of this licence, visit http://creativecommons.org/licenses/by/4.0/.

\section{References}

Barnes HA (1997) Thixotropy—a review. J Nonnewton Fluid Mech 70(1-2):1-33

Barnes HA (2000) A handbook of elementary rheology. Institute of Non-Newtonian Fluid Mechanics University of Wales

Bielski A, Zielina M (2017) The influence of selected parameters on coagulation efficiency modelling in the treatment of water from a Cretaceous catchment. Desalin Water Treat 99:289-298
Domoń A, Papciak D, Tchórzewska-Cieślak B, Pietrucha-Urbanik K (2018) Biostability of tap water-A qualitative analysis of health risk in the example of groundwater treatment (Semi-Technical Scale). Water 10(12):1764

Hendricks D (2001) Fundamentals of Water Treatment Unit Processes: Physical, chemical and biological. Taylor and Francis Group

Logsdon GS, Mason L, Stanley JB (1990) Troubleshooting an existing treatment plant. J New England Water Works Assoc 104(1):43-56

Logsdon GS, Hess A, Chipps MJ, Rachwal AJ (2002) Filter Maintenance and Operations Guidance Manual. American Water Works Association

Mackie RI, Dąbrowski W, Zielina M (2003) Numerical study of a rational rule for the operation of variable declining rate filters in response to changes in raw water quality. Environ Prot Eng 29(1):45-51

Michel MM, Siwiec T, Reczek L, Duda C (2017) Removing aggressive carbon dioxide from water using melaphyre bed. J Ecol Eng 18(5):186-191

Mroczko D, Zimoch I (2020) The use of zeta potential measurement as a control tool of surface water coagulation. J Ecol Eng 21(3):237-242

Pietrzyk A, Papciak D (2018) The effectiveness of organic matter removal in unit processes of the technological groundwater treatment system. E3S Web of Conf 44:00142. https://doi.org/10.1051/ e3sconf $/ 20184400142$

Sillanpää M, Ncibi MC, Matilainen A, Vepsäläinen M (2018) Removal of natural organic matter in drinking water treatment by coagulation: A comprehensive review. Chemosphere 190:54-71

Tien C, Ramarao BV (2007) Granular Filtration of Aerosols and Hydrosols, 2nd edn. Elsevier Science

Uragami T (2017) Science and Technology of Separation Membranes. Wiley

Zielina M (2011) Particle shapes in the drinking water filtration process, clean - soil. Air, Water 39(11):941-946

Zielina M (2016) Monitoring particle size distribution for water treatment processes. Environ Prot Eng 42(3):167-177

Zielina M, Dąbrowski W (2011) Impact of raw water quality on operation of variable declining rate filter plants. Environ Prot Eng 37(2):133-140

Publisher's Note Springer Nature remains neutral with regard to jurisdictional claims in published maps and institutional affiliations. 